ILA الجمعية المصرية للقر اءة و المعرفة عضو الجمعية الدولية للمعرفة

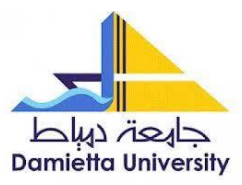

كلية التربية

قسم المناهج وطرق التدريس

\title{
استراتيجية مقترحة قائمة على الحقول الدلالية الصرفية لتنمية مهارات الأداء الكتابى لطلاب الصف الأول الثانوى
}

\author{
إعداد \\ د/ أسماء محمود الشحات \\ مدرس بقسم المناهج وطرق التدريس \\ كلية التربية - جامعة دمياط
}




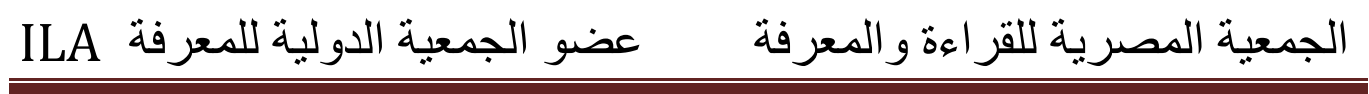


تعد الكتابة من أعظم ما أنتجه العقل البشرى، فسجل بها الإنسان نشأته ومسيرته وغايته،




الأكاديمى فى كافة المراحل الدراسية.

وتأتى أهميتها فى تعلم الطالب مواجهة المواقف الحياتية التى تتطلب منه إرسال بطاقة

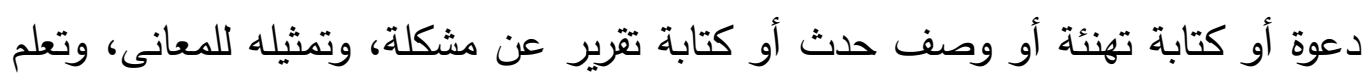

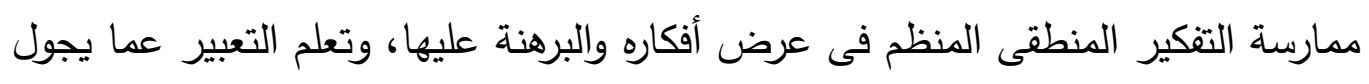

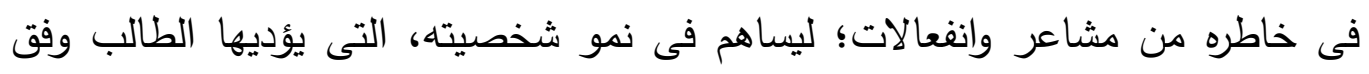

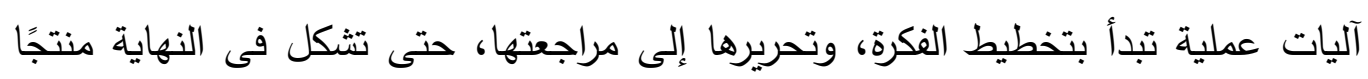

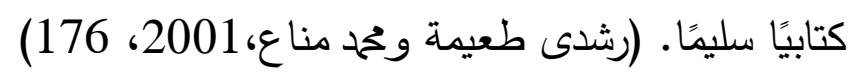

فالأداء الكتابى المستخدم سواء فى عرض معلومات أو فى التعبير عن فكرة خاصة

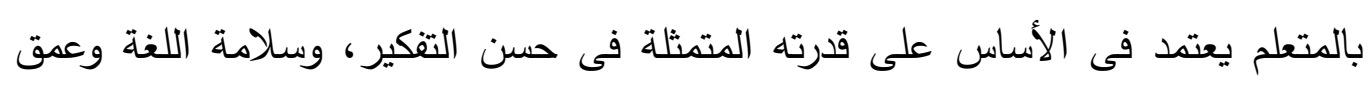

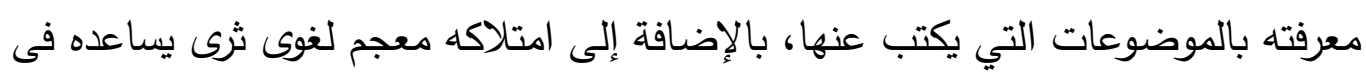
مواجهة المواقف الكتابية التى يتعرض لها أثناء دراسته.

ولما كان الأداء الكتابى مرتبطًا بالثروة اللغوية لاى الفرد، فيستطيع أن يعبر عن الموقف



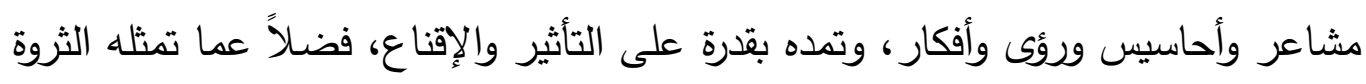



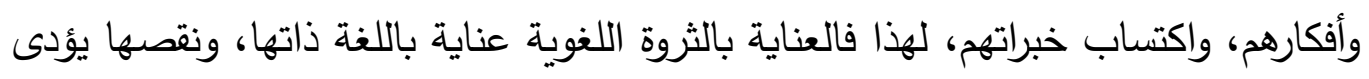


التعبير عن مشاعره وأفكاره بصورة طليقة. 


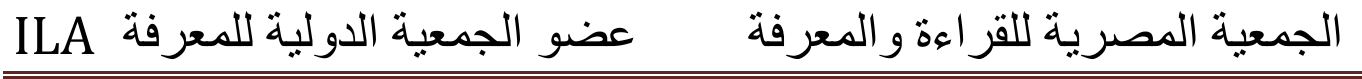

وليس الهدف من تعلم أية لغة يكمن فى حفظ كلمات جديدة، ولكن لابد من تعرف الأنماط الصوتية للكلمات، وكذلك طرق تأليفها لتكون جملً، وكيفية التعبير عن المعنى بطرق

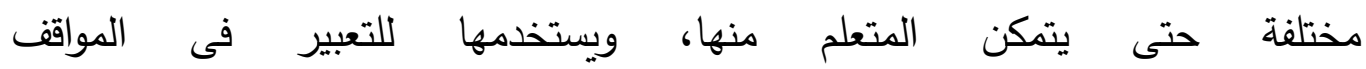
المختلفة.(Baker,2003,349)

وتعد المفردات من أبرز مكونات اللغة، وتمثل الأساس الذى تقوم عليه عملية الاتصال والتواصل، وبالرغم من ذلك فالمتعلمون يواجهون صعوبة كبيرة فى تعلم المفردات اللغوية، ويعزى ذلك إلى طبيعتها المتامية؛ لذا فهناك حاجة إلى مساعدة الطلاب لاكتساب المفردات اللغوية، وتعزيز تعلمها من خلال التغذية الراجعة المقدمة من المعلم، وتوظيف



إذًا فاللغة تستقى أهميتها من مفرداتها، ونظرًا للأهمية التى يكتسبها هذا الجانب من اللغة فقد عنى مخططو البرامج اللغوية بوضع مقاييس عالمية- وفق أسس علمية- لاختيار

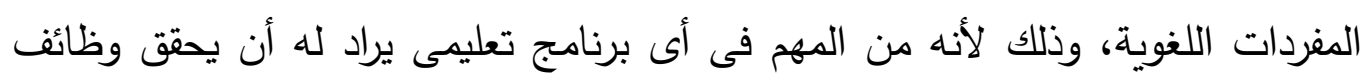

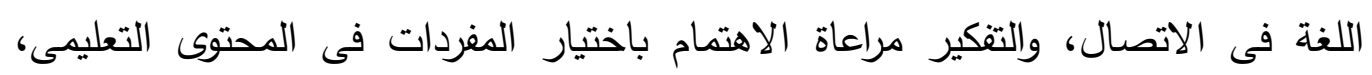
وكيفية تتميتها لدى الباحث. (محمود جلال،2019، 89)

واكتساب المفردات اللغوية يرتبط بتصنيفاتها وفقًا للحقول الدلالية التى تتمى إليها وذلك ما أوضحه(Qian,D\& Schedl,M, 2004) بأن:

- حجم المفردات اللغوية هو مركز عملية اكتساب المفردات، ويتضمن معرفة سمات المفردات اللغوية، وخصائصها، مثل: سماتها الصرفية، والصوتية، والالالية، والنظمية، وكل هذه السمات تؤدى دورًا مهما فى استيعاب

$$
\text { النصوصن - (النص }
$$




\section{الجمعية المصرية للقر اعة والمعرفة عضو الجمعية الدولية للمعرفة}

- اكتساب المفردات اللغوية يتحقق بمعرفة عدة مكونات لغوية، وهى: معرفة رسم الكلمة وهيكلها الخارجى كالقدرة على كتابة الكلمة ونطقها بشكل سليم، ومعرفة بنية الكلمة وهيكلها، مثل: (معرفة الهيكل الصرفى، واشتقاق الكلمات والنظام النحوى التركيبى فى الجملة كمعرفة العلاقة التركيبية، ومعرفة معانى الكلمات)، ومعرفة علاقة المفردات الارتباطية مع الكلمات الأخرى، مثل: (الترادف، والتضاد، والقدرة على إقامة الروابط العضوية بين الكلمات).

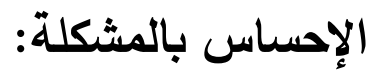

تعد الكتابة من أهم الوسائل التى تستخدم لحفظ التراث، فهى تحدث فى عدد من السياقات الموقفية والاجتماعية لتخدم عددًا من الأغراض، ويرتبط فيها السياق بالهدف فى حالات كثيرة، فالكتابة الجيدة كما يذكر محمود جلال (2009) ليست خيارًا، بل هى ضرورة كالفهم القرائى وهى متطلب أساسى للنجاح الأكاديمى، والمشاركة فى الأنشطة الحياتية بفاعلية، ذلك أن أكثر سياقات الحياة تتطلب مستوى من المهارة فى الكتابة، وهى طراز تتداخل فيه عوامل مختلفة، وتتأثر بمؤثرات متباينة، فالكاتب الماهر هو الذى يكيف كتابته مع السياق الذى يكتب فيه. (محمود جلال ، 2009، 183)

وبالرغم من أهمية الأداء الكتابى وتتميته، فان الواقع يشير إلى هناك ضعفًا واضحًا



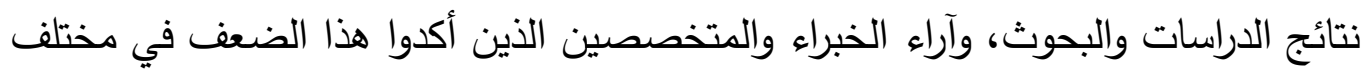
المراحل التعليمية، بالإضافة إلى ضعف درجات الطلاب فى اختبارات الأداء الكتابى بالمدارس.

وضعف مستويات الأداء الكتابى -كناتج أساسى للضعف اللغوى- في المرحلة الثانوية أمر لا يحتاج إلى دليل، فيرجع هذا الضعف إلى ضعف الثروة اللغوية وتباعد الأفكار، وسطحية المعالجات ، وعدم الاهتمام بالإنتاج الكتابى، كما أن هناك قصورًا فى سياقات 


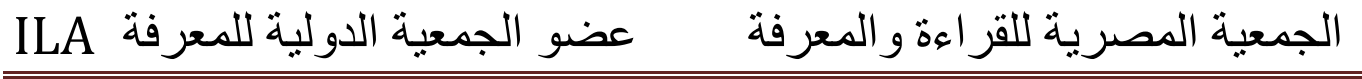

تعليم الكتابة، ويرجع ذلك إلى أن المعالجات التدريسية تعتمد على تدريس الثق اللغوى للكتابة مع إهمال منطقتين أساسيتين هما الثق المعرفى والتدريب المهارى. وتزداد حدة هذه المشكلة بوجود أعداد كبيرة من المتعلمين فى المستويات التعليمية المختلفة

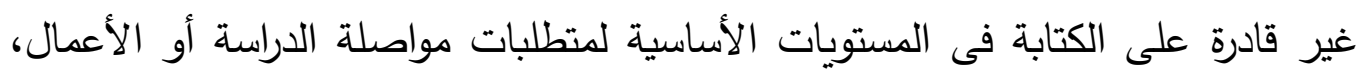

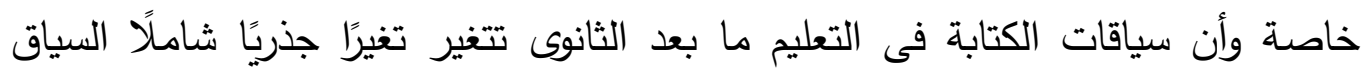
والغرض والكم، كما أن افتقار مهارات القراءة والكتابة يؤدى إلى تباين واضح بين مستويات

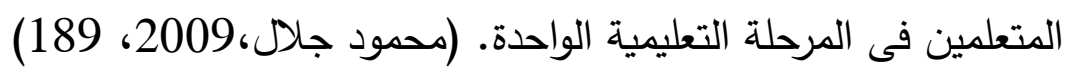

واهتمت بعض الدراسات ببناء برامج لتتمية مهارات الأداء الكتابى، فتعددت برامج تتميتها،

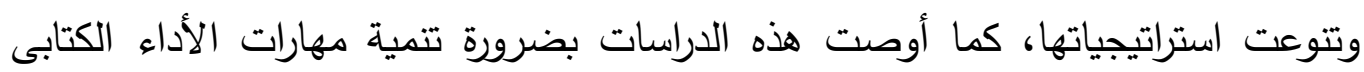
لدى الطلاب باستخدام مداخل واستراتيجيات حديثة تتلاءم وطبيعة عملية الكتابة، ومن هذه الدراسات: دراسة (على الحلاق: 2007) التى هدفت إلى استخدام استراتيجيات التعبير


طلبة الصف الأول الثانوى بالأردن، ودراسة (ماهر عبد البارى: 2008) التى هدفت إلى تعرف أثر برنامج قائم على استراتيجيات ما وراء المعرفة فى تتمية الأداء الكتابى لدى طلاب الصف الثانى الثانوى، وتوصلت الدراسة إلى إثبات فاعلية استراتيجيات ما وراء المعرفة فى تتمية مهارات الأداء الكتابى التعبيرى، وفى تتمية مهارات كل عملية من عمليات الكتابة، ودراسة (على عبد المنعم،2012) التى أكدت أن واقع تعليم الكتابة فى وفى

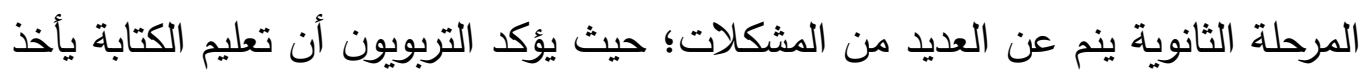

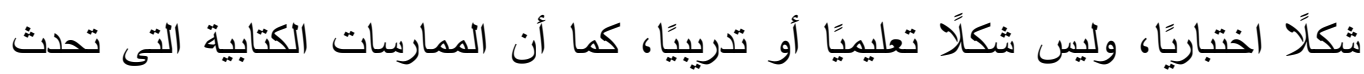
داخل الفصول الدراسية تتم فى إطار محدود، ولا يستخدم الأداء الكتابى لذاته بل لإظهار قدرة الطالب على تتظيم المعرفة، ودراسة(سلوى بصل: 2015) التى هدفت إلى تتمية بعض مهارات الأداء الكتابى فى ضوء عمليات الكتابة لدى طلاب الصف الأول الثانوى لئى باستخدام برنامج مقترح قائم على التعلم المنظم ذاتيًا، وأوصت الدراسة بضرورة اهتمام 




واضعى مناهج اللغة العربية ومطوريها بإعداد مقررات لتعليم الكتابة فى ضوء المستويات


فى مجالاتها وفنونها المتتوعة، وهدفت دراسة (سامى هزايمة: 2017) إلى بحث أثر استخدام السبورة التفاعلية فى تحسين مهارة الكتابة الأدائية لدى طلبة الصف الثانى الأساسى فى دولة الإمارات العربية المتحدة، وهدفت دراسة (إنتصار عطية، 2019) إلى دانى تعرف فاعلية برنامج مقترح قائم على استراتيجية التعلم التعاونى لتنمية بعض مهارات الأداء الكتابى فى ضوء عمليات الكتابة لدى طالبات الصف الثالث الثانوى. من خلال العرض السابق نبعت فكرة البحث الحالى كمحاولة علمية لتنمية مهارات الأداء الكتابى فى ضوء استراتيجية قائمة على الحقول الدلالية الصرفية، وفى حدود علم الباحثة

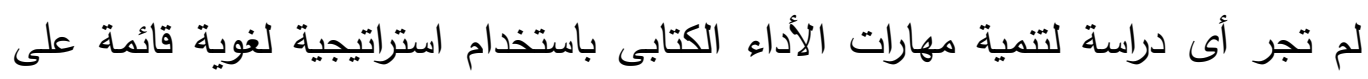
الحقول الدلالية الصرفية تركز على تزويد المتعلمين بمجموعة من المفردات الاشتقاقية

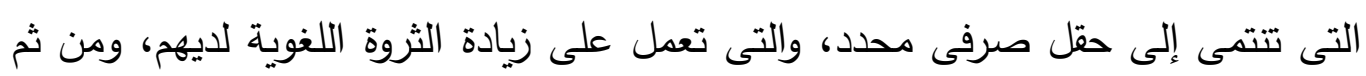
توظيفها فى الكتابة.

ونظرية الحقول الدلالية من النظريات الحديثة التى يمكن أن تسهم فى ذلك، والحقول الصرفية تعد نتيجة لتطور عملية التصنيف فى الحقول الدلالية، حيث تتابعت الرسائل الموضوعية التى عمدت إلى التصنيف الصرفى، فكثرت الرسائل اللغوية فى الإبدال والأبنية، كما تطورت إلى التثريع الصوتى المبنى على الأصوات الذى أضحى فى ضوء النظرية الدلالية مقياسًا يعول عليه فى توزيع النظام اللسانى إلى مجموعات متميزة تكوّن الانى فى مجملها نسقًا أو شبكة العلاقات لهذا النظام.

ويمكن القول إن الحقول الصرفية وسيلة لعرض الألفاظ وتجديد الدلالات ونموها، وإذا كان الاشتقاق هو أخذ كلمة من كلمة، أو توكيد لفظ من لفظ ، فإن التصريف هو ميزان لهذه الكلمات المشتقة، ودليل الباحث فى موضوع الاشتقاق، ذلك أن صيغة الكلمة أو وزنها 


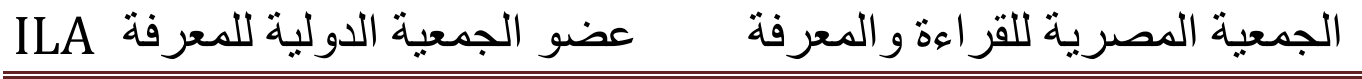

عنصر من عناصرها الأساسية التى تحدد معناها ومدلولها، ومن خلال صيغة الكلمة نستطيع أن نزيل الالتباس والغموض بين معانى الألفاظ المشتقة من مادة واحدة، فالصيغة هى التى تقيم الفروق بين كاتب ومكتوب ومكاتبة.

وبمراجعة الدراسات والبحوث التى أجريت فى مجال الحقول الدلالية الصرفية اتضح - فى حدود علم الباحثة- أنه لا توجد دراسة فى مجال المناهج وطرق التدريس تربط الحقول الدلالية الصرفية بالأداء الكتابى في المرحلة الثانوية مما ييرز الحاجة إلى تطبيقات هذه النظرية فى مجال تعليم اللغة العربية، ومعظم الدراسات التى تتاولت هذه النظرية دراسات أكاديمية، وهناك دراسات قليلة اعتمدت على الحقول الدلالية لتمية مهارات الإبداع اللغوى والتواصل الثفوى، كدراستى: (محمد ناثر، 2011) والتي هدفت إلى دراسة فاعلية نظرية الحقول الدلالية فى التعبير الوصفى لتنمية مهارة الكلام لاى طلاب مدرسة المعارف الثانوية الإسلامية الخاصة، وأكدت الدراسة فاعلية النظرية فى تتمية مهارة الكلام، كما أوصت بضرورة تطبيق هذه النظرية لاستيعاب المهارات الأربع الاستماع والكلام والقراءة فالكتابة، ودراسة (آية نصر، 2016) التى هدفت إلى اقتراح استراتيجية فى ضوء نظرية الحقول الدلالية لتنمية بعض مهارات الإبداع اللغوى لدى طلاب المرحلة الثانوية.

\section{تحديد المشكلة:}

تتمثل مشكلة البحث فى ضعف طلاب الصف الأول الثانوى فى مهارات الأداء الكتابى، ويرجع هذا الضعف إلى أسباب متعددة منها غياب البرامج التربوية المعدة لتنمية تلك المهارات، وقصور الطرق المتبعة فى تتمية تلك المهارات، وضعف الحصيلة اللغوية لدى مئ الطلاب مما يبرز الحاجة إلى تتمية تلك المهارات باستخدام مداخل واستراتيجيات حديثة لعل أبرزها الحقول الدلالية الصرفية.

ويتصدى البحث الحالى لهذه المشكلة من خلا الإجابة عن الأسئلة الآتية: 1. ما مهارات الأداء الكتابى اللازمة لطلاب الصف الأول الثانوى؟ 


\section{ILA الجمعية المصرية للقر اءة والمعرفة عضو الجمعية الدولية للمعرفة}

2. ما مستويات طلاب الصف الأول الثانوى فى مهارات الأداء الكتابى؟

3. ما الاستراتيجية المقترحة لتتمية مهارات الأداء الكتابى لدى طلاب الصف

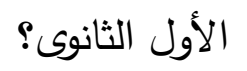

4. ما فاعلية الاستراتيجية المقترحة فى تنمية مهارات الأداء الكتابى لدى

$$
\text { طلاب الصف الأول الثانوى؟ }
$$$$
\text { حدود البحث: يقتصر هذا البحث على: }
$$

1. بعض مهارات الأداء الكتابى التى تتوافق مع الحقول الدلالية الصرفية.

2. مجموعة من طلاب الصف الأول الثانوى بمدرسة الروضة الثانوية.

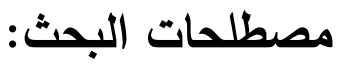

الأداء الكتابى: تعرف الباحثة هذا المصطلح تعريفًا إجرائيًا بأنه: إنتاج لغوى يوظف فيه الطالب ثروته اللغوية من المفردات الاشتقاقية الصرفية فى موضوع واحد لبناء فقراته والتعبير عن فكره.

الحقول الدلالية الصرفية: تعرف الباحثة هذا المصطلح تعريفًا إجرائيًا بأنه: مجموعة من المفردات أو الأوزان الاشتقاقية التى تثتمل على مفاهيم تتدرج تحت مفهوم عام يحدد الحقل.

\section{أدوات البحث ومواده:}

1. استبانة تتضمن قائمة مهارات الأداء الكتابى اللازمة لطلاب الصف الأول 


\section{الجمعية المصرية للقر اعة والمعرفة عضو الجمعية الدولية للمعرفة}

2. اختبار لقياس مستويات طلاب الصف الأول الثانوى فى مهارات الأداء

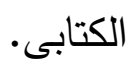

3. دليل المعلم؛ لتتمية مهارات الأداء الكتابى فى ضوء استراتيجية قائمة على



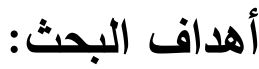

هدف البحث الحالى إلى تنمية مهارات الأداء الكتابى لاى طلاب الصف الأول الثانوى



1. وصف واقع تدريس مهارات الأداء الكتابى لاى طلاب الصف الأول الثانوى. 2. تفسير أسباب تدنى مستوى طلاب الصف الأول الثانوى فى مهارات الأداء

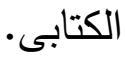

3. التتبؤ بتحسن مستوى طلاب الصف الأول الثانوى فى مهارات الأاء الكتابى؛ نتيجة لتدريس الاستراتيجية القائمة على الحقول الدلالية الصرفية.

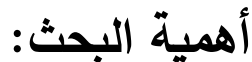

1. الأهمية النظرية: يقدم البحث الحالى إطارًا نظريًا حول نظرية الحقول الدلالية

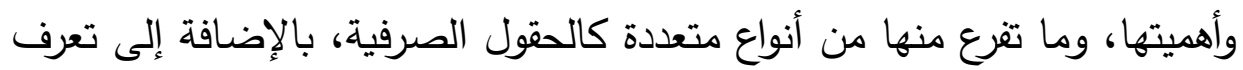
كيفية جمع المفردات وتصنيفها فى ضوء النظرية، وكيفية بناء الحقول الصرفية



2. الأهمية التطبيقية: يقدم البحث الحالى قائمة بمهارات الأداء الكتابى يمكن أن يستفيد منها المعلمون والموجهون والقائمون على تعليم طلاب الصف الأول 


\section{الجمعية المصرية للقر اعة والمعرفة عضو الجمعية الدولية للمعرفة}

الثانوى، واختبارًا لقياس مهارات الأداء اللغوى لطلاب هذا الصف، ودليلاً للمعلم يتضمن الاستراتيجية المقترحة؛ لتتمية تلك المهارات.

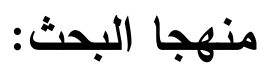

يستخدم البحث المنهجين: الوصفى فى التأصيل النظرى للمفاهيم النظرية لنظرية الحقول

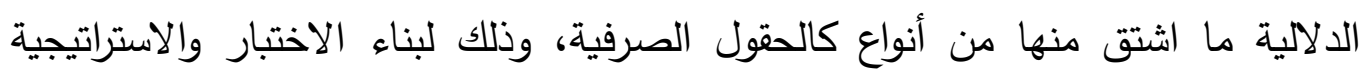
المقترحة، وشبه التجريبى لتعرف فاعلية الاستراتيجية المقترحة فى تتمية مهارات الأداء



فروض البحث: يسعى البحث الحالى إلى اختبار صحة الفروض الآتية: 1. تقل مستويات طلاب الصف الأول الثانوى عن مستوى (50\% ) فى مهارات

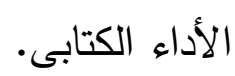

2. يوجد فرق دال إحصائًا > 0.05 بين منوسطى درجات الدجموعة التجريبية فى التطبيقين القبلى والبعدى فى اختبار مهارات الأداء الكتابى لصالح التطبيق

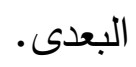

3. تحقق الاستراتيجية المقترحة درجة فاعلية كبيرة فى تتمية مهارات الأداء الكتابى

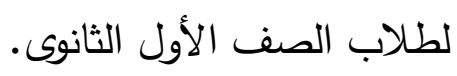
إجراء ات البحث:

للإجابة عن أسئلة البحث، والتحقق من صحة فروضه، قامت الباحثة بالإجراءات التالية: أولاً: للإجابة عن السؤال الأول، والذى ينص على: ما مهارات الأداء الكتابى اللازمة

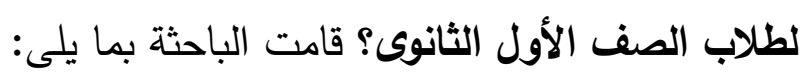




\section{الجمعية المصرية للقر اعة والمعرفة عضو الجمعية الدولية للمعرفة}

إعداد صورة مبدئية لقائمة بمهارات الأداء الكتابى، اللازمة لطلاب الصف الأول الثانوى، من خلال الاطلاع على الدراسات، والأدبيات التى تتاولت تتمية مهارات

$$
\text { الأداء الكتابى. }
$$

عرض القائمة على مجموعة من الخبراء، والمحكمين فى مناهج وطرق تدريس

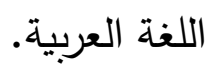

إجراء التعديلات المطلوبة فى ضوء آراء الخبراء والمحكمين، ووضع القائمة المقترحة فى صورتها النهائية.

ثانيًا: للإجابة عن السؤال الثانى، والذانى ينص على: ما مستويات طلاب الصف الأول الثانوى فى مهارات الأداء الكتابى؟ قامت الباحثة بما يلى لهابه

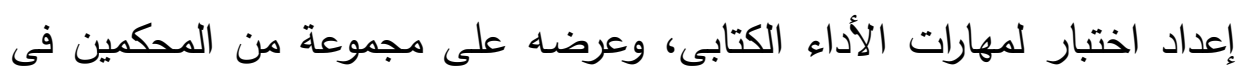
مجال المناهج، وطرق تدريس اللغة العربية . تطبيق الاختبار على عينة عشوائية من طلاب الصف الأول الثانوى. رصد النتائج ومعالجتها إحصائيًا؛ لحساب متوسط الأداء فى الاختبار ، وتحديد المستويات. ثالثًا: للإجابة عن السؤال الثالث، واللى ينص على: ما الاستراتيجية المقترحة لتنمية مهارات الأداء الكتابى لدى طلاب الصف الأول الثانوى؟ قامت الباحثة بما يلى: دراسة نظرية لنظرية الحقول الدلالية وأنواعها. إعداد التصور للاستراتيجية المقترحة؛ لتتمية مهارات الأداء الكتابى. إعداد دليل للمعلم يتضمن تلك الاستراتيجية؛ ليسترشد بها المعلم فى تتمية تلك

عرض الدليل على مجموعة من الخبراء والمحكمين؛ لتحديد مدى صلاحيته. تعديل الدليل فى ضوء آراء الخبراء والمحكمين ووضعه فى صورته النهائية. 


\section{الجمعية المصرية للقر اعة والمعرفة عضو الجمعية الدولية للمعرفة}

رابعًا: للإجابة عن السؤال الرابع، والذأى ينص على: ما فاعلية الاستراتيجية المقترحة فى تتمية مهارات الأداء الكتابى لدى طلاب الصف الأول الثانوى؟ قامت الباحثة بما يلى: • تطبيق الاختبار قبليًا على عينة البحث.

$$
\text { • تجريب البرنامج المقترح على عينة البحث. }
$$

رصد النتائج ومعالجتها إحصائيًا، وكتابة التوصيات والمقترحات البحثية.

\section{الإطار النظرى والدراسات السابقة}

لما كان البحث الحالى معنيًا بتتمية مهارات الأداء الكتابى من خلال استخدام استراتيجية قائمة على الحقول الدلالية الصرفية، فمن هذا المنطلق يجب التعريف بمصطلحات البحث، والمحاور المتضمنة بكل مصطلح، وفيما يلى تفصيل لذلك:

$$
\text { (أ) مفهور الأول: الأداء الكتابى: }
$$

لقد تعددت الأدبيات التى تناولت مفهوم الأداء الكتابى، ومنها:

- تعريف أحمد عوض بأنه استكتاب طلاب العينة من خلال موقف تعليمى متكامل قبل تطبيق البرنامج وبعده، وذلك فى ضوء أنشطة كتابية اتصالية، ثم تحلل كتاباتهم وفق معايير للحكم على صحة المكتوب، ووفائه بالغرض الوظيفى

$$
\text { الاتصالى الذى كتب من أجله. (أحمد عوض،2000، 306) }
$$

• تعريف مرفت البسيونى بأنه قدرة الطالبة على إنتاج موضوعات ومقالات أدبية مقبولة من حيث المحتوى والتنظيم وفنيات الكتابة، ويقاس بالدرجة التى تحصل 


\section{الجمعية المصرية للقر اعة والمعرفة عضو الجمعية الدولية للمعرفة}

عليها الطالبة فى اختبار التعبير الكتابى بنوعيه الوظيفى والإبداعى المعد لهذا الغرض فى الدراسة الحالية. (مرفت البسيونى، 2019، 454) تعريف أمانى بدر بأنه استخدام التلاميذ عناصر البناء التعبيرى الحروف والكلمات والجمل والفقرات كأدوات لاستخلاص الأفكار حول موضوع واحد، ومن أكثر من بعد، واستخلاص المعلومات من القراءة، ووصف أغراض متضمنة فيها وصفًا ظاهيًا وتعبيريًا وفق آليات الكتابة، وقواعد اللغة والثكل والتتظيم. (أمانى بدر ، (11، 2019

ومن خلال العرض السابق لتعريفات الأداء الكتابى، يمكن تعريف الأداء الكتابى بأنه قدرة الطلاب على إنتاج نصوص متكاملة من خلال استخدام عناصر البناء التعبيرى، وترتيب



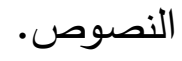

\section{(ب) أهمية الأداء الكتابى:}

يعد التعبير أو الأداء الكتابى قناة الاتصال الإنسانى وآداة من أهم أدواته، حيث يمكن

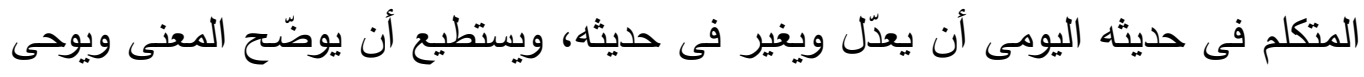



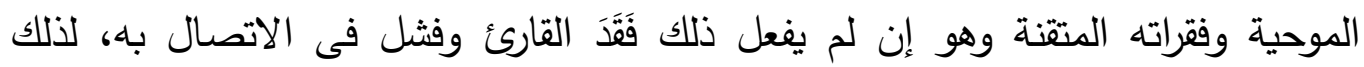

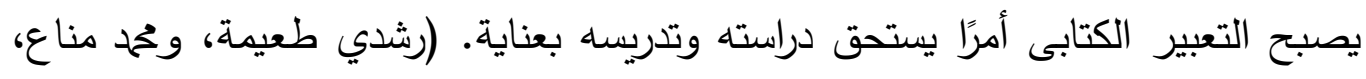
(176، 2001

ويمكن القول بأن أهمية الأداء الكتابى للطالب تتمثل فى القيمة التربوية التى يقدمها لهم، التهاء

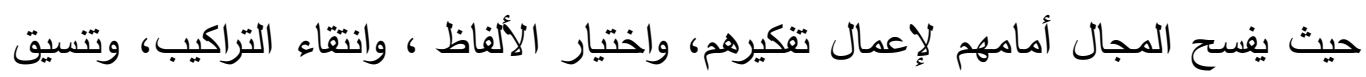

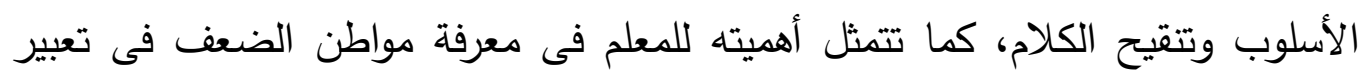




\section{الجمعية المصرية للقر اءة والمعرفة عضو الجمعية الدولية للمعرفة}

الطلاب لعلاجها، وإدراك المستوى الذى وصلوا إليه فى الكتابة؛ ليبنى عليه دروسه المستقبلية.

\section{(ج) أسباب ضعف الأداء الكتابى لدى الطلاب:}

إن الأداء الكتابى المستخدم فى عرض معلومات أو التعبير عن فكرة خاصة بالطالب يعتمد فى الأساس على قدرته المتمثلة فى حسن التفكير، وسلامة اللغة، وعمق معرفته بالموضوعات التى يكتب عنها، وأدى عدم توافر ذلك إلى ضعف الألى الأداء الكتابى لدى الطلاب، ويرجع البعض أسباب هذا الضعف إلى أمور متعددة، منها:

• ضعف المحصول اللغوى، ويتمثل فى الثروة اللغوية وهى السبيل إلى الاتصال الواضح المفهوم، فمن دونها لا يمتلك الكاتب مادة التعبير وأدواته.

• ضعف المحصول المعرفى أو الرصيد الثقافى والفكرى والعلمى، فالكاتب الجيد هو فى الأصل قارئ جيد؛ لذا فكثرة القراءة تساعد على اتساع الآفاق المعرفية والفكرية. " ضعف المحصول الفنى ويتمثل فى ضعف المهارات الكتابية من مهارات لغوية، وأسلوبية، وإملائية. (تحمد النجار، أحمد الهوارى، سعد مصلوح، 2001، 20)

بينما يرجع البعض أسباب ضعف الأداء الكتابى إلى أسباب أخرى، هى: عدم وجود مواد تعليمية مناسبة لتعليم الكتابة. عدم استخدام أساليب واستراتيجيات ومداخل فعالة لتدريس هذه المهارة. عدم ربط تعليم الكتابة والتعبير بحاجات التلميذ وخبراته واهتماماته. عدم تخصيص الوقت الكافى لتدريس هذه المهارة. عدم ربط تعليم التعبير بمواد المنهج الأخرى. 




وجود اتجاهات سلبية نحو هذه المهارة من التلاميذ والمدرسين والآباء.

ممارسة الكتابة فى مواقف تقليدية تحول دون اهتمام التلاميذ نحو تعلم كتابة

صحيحة.

اهتمام المعلم بحصص التعبير الكتابى والإملاء والخط ضعيف جدًا فى الجدول

$$
\text { المدرسى. (مختار حسين، 2006، 14) }
$$

\section{(د) أدوار المعلم فى تنمية مهارات الأداء الكتابى:}

يؤدي المعلم دورًا أساسيًا لتتمية مهارات الكتابة (التتظيمية- الفكرية- الأسلوبية- الصحة اللغوية..) عند التلاميذ فى جميع المراحل الدراسية، والكتابة عملية معقدة، تتطلب درجة من السيطرة على اللغة، وكفاءة من الكاتب إذا أراد لكتابته أن تكون ذات فاعلية، كما تتضمن مستوى مختلفًا من التعبير اللغوي حين تقارن بالمنطوق، فهى وسيلة أكثر احتواء على العناصر العقلية، وتقوم بوظيفتها خالية من وسائل التعبير الفنية الموجودة فى الصوت الإنسانى، كما تؤدى هذه الوظيفة من دون مصاحبة حركات الوجه، والإشارات

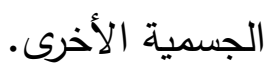

وهى عملية يشترك فى تكوينها عناصر كثيرة، فهناك مكونات عديدة تدخل فى عملية إنتاج المكتوب، منها ما يرتبط بالجانب النفسى الإدراكى، ومنها ما يرتبط بالجانب اللغوى، كما أن لها أبعادًا اجتماعية وعاطفية مختلفة، فالكتابة نشاط معقد إلى حد كبير؛ الألى لأنها نتيجة لتضافر عدد من العمليات التى تحدث فى نفس الوقت كإصدار الأحكام على المعلومات،

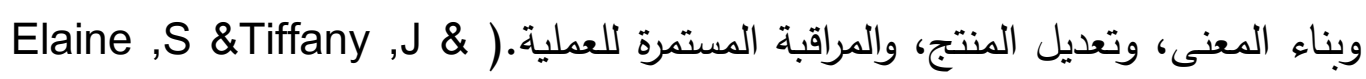
(Louise ,W:2000, 45-64

لذلك فمن الجدير بمعلم اللغة العربية أن يكون على قدر عال من الكفاءة والفعالية، والتمكن مهنيًا وأكاديميًا، وذلك لأنه منوط به إكساب التلاميذ مجموعة من المهام، ومن لأن 


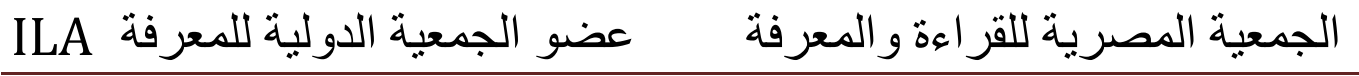

أبرزها: إعطاء قدر من الاهتمام للغة المنطوقة(الكلام) مع عدم تجاهل مهارات اللغة

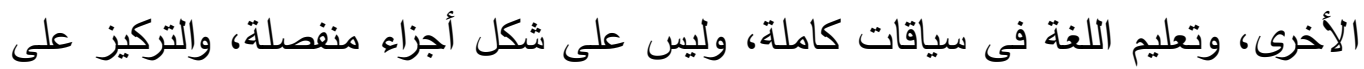
الجانب الوظيفى للغة، والتخطيط المسبق للطرق التى تجعل معانى المفردات اللغوية واضحة للطلاب، وتوفير مواقف لاستخدام اللغة بشكل هادف من خلال الأنشطة الاتصالية، وتخطيط دروس القراءة على نحو يزود التلاميذ بخبرات لغوية غنية، وإكسابهم لمهارات الكتابة من خلال دمج أنشطة الكتابة بما يقود تدريجًا إلى تعبير أكثر إبداعية

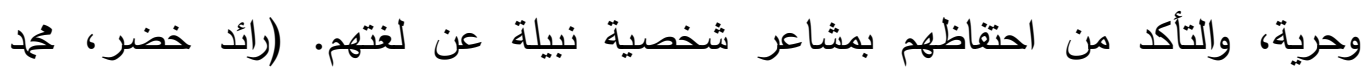

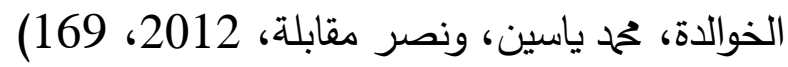

علاوة على ما سبق هناك مجموعة من المهام يجب أن يضعها المعلم موضع التطبيق، فالكتابة ليست وسيلة لتثبيت أفكار فحسب، بل تستخدم بشكل مخطط فى توليد الأفكار، لذا فهى تتضمن عددًا من المهارات المركبة، والمتشابكة فى آن واحد، وهذه المهارات صنفها ماهر عبد البارى(2010، 85) كما يلى:

1. مهارات تتظيمية، وهذه المهارات تضم مهارات ترتبط بكل من: المقدمة، وصلب

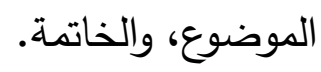

2. مهارات فكرية: من مراعاة وضوح الأفكار وسلامتها، وترابطها، واتساقها، وترتيبها،

ومنطقيتها.

3. مهارات أسلوبية: وتتمثل فى سلامة (الألفاظ، الجمل، العبارات، والفقرات، وجمال الأسلوب، مناسبة الأسلوب لمقام الجمهور ).

4. مهارات خاصة بآليات الكتابة: وتتمثل فى صحة الرسم الإملائى، وجمال الخط، وأدوات الربط، واتباع نظام الفقرات، مراعاة الهوامش العلوية والسفلية والجانبية. 5. مهارات الصحة اللغوية: وتتمثل فى سلامة الألفاظ والجمل والعبارات مبنى ومعنى. 


\section{الجمعية المصرية للقر اعة والمعرفة عضو الجمعية الدولية للمعرفة}

المحور الثانى: الحقول الدلالية الصرفية: مفهومها، نشأتها، أهميتها، أنواعها:

\section{(أ) مفهوم الحقول الدلالية الصرفية:}

هى مجموعة من الأوزان الاشتقاقية تلاحظ فى اللغة العربية بصورة أوضح مما فى اللغات الأخرى، وتُصنف الوحدات فى هذا المجال بناء على قرابة الكلمات فى ضوه الؤه العلامات الصرفية التى تعد سمة صورية ودلالية مشتركة بينها داخل الحقل الواحد. (أحمد عمر، 1988، 80- 81؛ عبد الجليل لغرام، 2018، 224)

ويعرف سليمان فياض الحقول الصرفية للأفعال بأنها حقول الدلالات فى مجموعات الأفعال العربية فى أبوابها وأوزانها المختلفة. (سليمان فياض، 1990، 1992،

وتعد الحقول الصرفية نوعًا من أنواع الحقول الدلالية، وفيما يلى عرض لمفهوم الحقول الالالية وأنواعها وأسسها:

| مفهوم الحقول الدلالية: هناك عدة تعريفات للحقل الدلالى منها ما

$$
\text { يلى }
$$

- قطاع متكامل من المادة اللغوية يعبر عن مجال معين من الخبرة، بينما يعرف

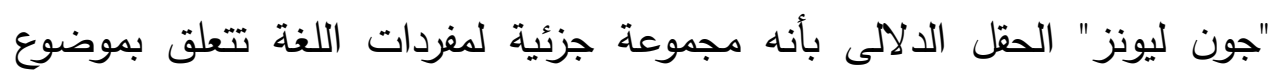
خاص وتعبر عنه. (عبد الجليل لغرام،2018، 219) - يعرف "جورج مونان" الحقل الدلالى بأنه مجموعة من الوحدات المعجمية التى تشتمل على مفاهيم تندرج تحت مفهوم عام يحدد الحقل. (أحمد عزوز،2002، 13) - مجموعة المعانى أو الكلمات المتقاربة التى تتميز بوجود عناصر أو ملامح دلالية مشتركة، وبذلك تكتسب الكلمة معناها فى علاقاتها بالكلمات الأخرى، لأن الكلمة لا 


\section{الجمعية المصرية للقر اءة والمعرفة عضو الجمعية الدولية للمعرفة}

معنى لها بمغردها، بل إن معناها يتحدد ببحثها مع أقرب الكلمات إليها فى إطار

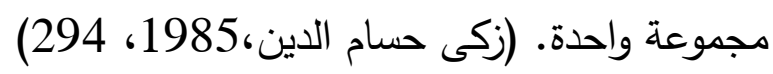

| أنواع الحقول الدلالية: يقسم الارسون الحقول الدلالية إلى أنواع، وهى كالآتى:

الكلمات المترادفة والكلمات المتضادة: التى تكون العلاقة بينها على شكل التضاد؛ لأن النقيض يستدعى النقيض فى عملية التنكير والمنطق، فعندما نطلق حكمًا ما نتأكد من صحته وتماسك بنيته، ومن هنا تنثأ الحقول المتناقضة. • الحقول التركيبية: وتثمل مجموع الكلمات التى ترتبط فيما بينها عن طريق

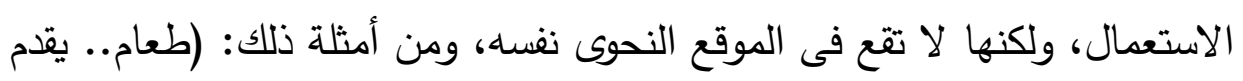
- يرى..عين - فرس. .صهيل). ه الحقول متدرجة الدلالة: وهى التى تكون فيها العلاقة متدرجة بين الكلمات، فقد ترد

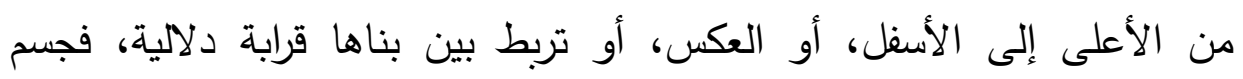

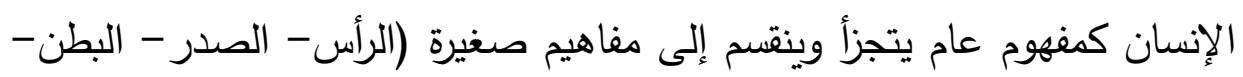

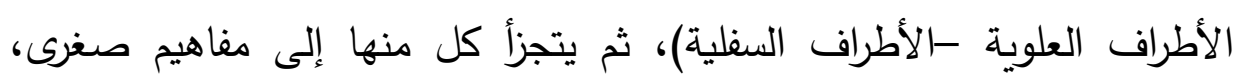

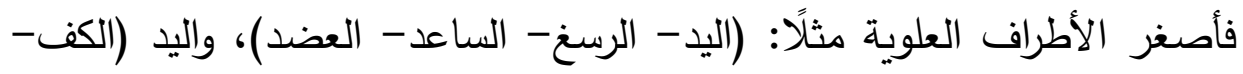



الحقول الصرفية: هى مجموعة من الأوزان الاشتقاقية تلاحظ فى اللغة العربية

$$
\text { بصورة أوضح مما فى اللغات الأخرى. }
$$

\# أسس نظرية الحقول الدلالية: تقوم نظرية الحقول الدلالية على مجموعة من

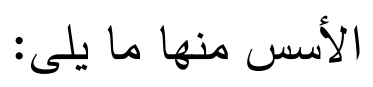




\section{الجمعية المصرية للقر اعة والمعرفة عضو الجمعية الدولية للمعرفة ILA}

أن الوحدات المعجمية(الألفاظ والكلمات) تؤلف فيما بينها شبكة من العلاقات الدلالية، وليست وحدات مستقلة منفصلة بعضها عن بعض.

هذه الوحدات يجمعها سياق دلالى خاص بها قد يتداخل أحيانًا مع سياقات أخرى مادية أو معنوية.

العقل البشرى يعمل من خلال اللغة، ومن ثم فإنه يحتفظ بهذه الوحدات فى الذاكرة بها، وما لها من صلة بالحقول أو المجالات التى تتتمى إليها هذه الوحدات المعجمية وليست وحدات منفصلة. (حلى خليل،2003، 378 ؛ صدلاح الدين زرال،2008، 192)

\section{أهمية نظرية الحقول الدلالية:}

• تتجلى قيمة نظرية الحقول الدلالية فى الهدف الذى تصبو إليه، وهو جمع كل كلمة وأختها مما جعلها تسهم بهذا فى إيجاد حلول لبعض المسائل اللغوية المعقدة، منها الكثف عن الفجوات المعجمية التى توجد داخل الحقل الدلالى وتسمى بالفجوة الوظيفية، وإيجاد كلمات مناسبة لشرح الأفكار والتعبير عما نريد. تحديد السمات التمييزية للمفردات اللغوية بعد جمعها مما يزيل كل لبس وحرج قد يعيق المتكلم فى استعمال الكلمات التى يظن أنها مترادفة، مما يتيح له الاستعمال الأمثل لمفردات اللغة.

الكثف عن العلاقات وأوجه الثبه والاختلاف بين الكلمات التى يجمعها حقل واحد، وبينها وبين المصطلح العام الذى يجمعها، فيتضح بذلك مجال استعمال كل كلمة بدقة.

(عبد الجليل منقور ،2001، 79) 


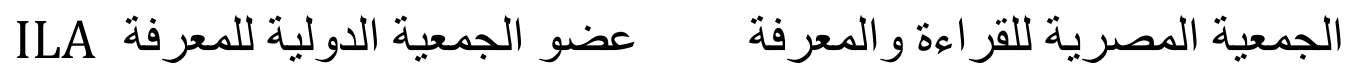

\section{(ب) نشأة الحقول الدلالية الصرفية:}

اهتم العلماء العرب قديمًا بمعانى الملفوظات حيث بذلوا جهودًا كبيرة، وأوقاتًا طويلة فى

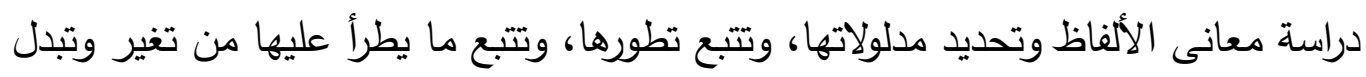



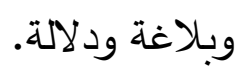

وعلم الصرف يعرف بأنه الحقل اللغوى الذى يدرس بنية الكلمة حيث يتعامل مع الكلمة

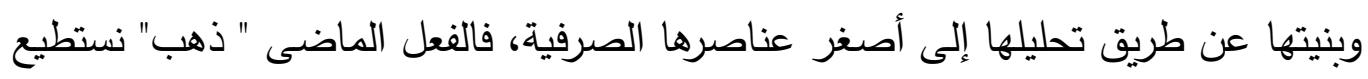

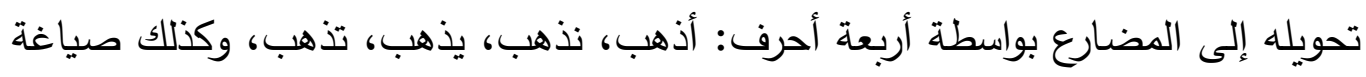
اسم الفاعل "ذاهب" من الفعل نفسه.

ولما تم توسيع مفهوم الحقل الدلالى ليضم الكلمات المترادفة والمتضادة، وكذلك الأوزان

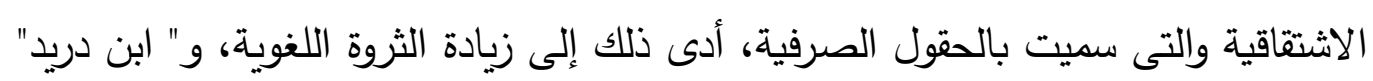

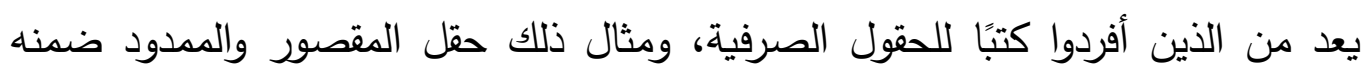

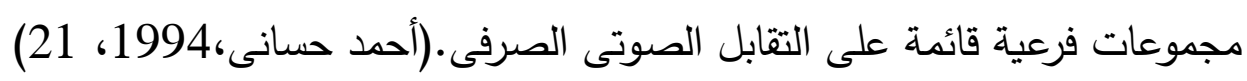
كما تم وضع معاجم لغوية عصرية حديثة مزودة بالتوصيفات العديدة للحقول الدلالية الصرفية، والتى تمكن اللغوى من الاطلاع عليها، وكل ذلك أدى لتتريب العربية من أبنائها ودارسيها.

(ج) أهمية الحقول الدلالية الصرفية: تبدو أهمية الحقول الدلالية الصرفية فى الجوانب التالية: • تتشيط الخلفية اللغوية للطلاب من خلال استدعاء الكلمات المرتبطة بمعنى أو

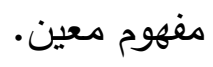




\section{ILA الجمعية المصرية للقر اءة والمعرفة عضو الجمعية الدولية للمعرفة}

$$
\text { • إدراك العلاقات والدلالات للكلمات التى يجمعها حقل دلالى واحد. }
$$

• تتظيم المعانى والعبارات اللغوية مما يؤدى إلى تتمية قدرة الطلاب على فهم



\section{(د) أنواع الحقول الدلالية الصرفية:}

1. الحقول الدلالية الصرفية للأفعال: الفعل الواحد قد تكون له أكثر من دلالة صرفية

بتغير مجالات معانيه، فمن أهم الدلالات الصرفية للفعل المضعف العين (فعّل) ما يلى: • الدلالة على التكثير والمبالغة مثل: جمّع: أكثر الجمع، وقتّل: أكثر القتل، وبالغ

• الدلالة على التعدية، مثل: علم زيد وعلّمته، فهم زيد وفهّمته، وفرح الرجل وفرّحته. الدلالة على الوجهة أو التوجه، مثل: غرّب الرجل، اتجه غربًا، وشرّق: اتجه شرقًا. • الدلالة على اختصار الحكاية، مثل: كبّر : إذ قال الله أكبر، وهلل: إذ قال لا إله إلا الله، وسبح: قال سبحان الله.

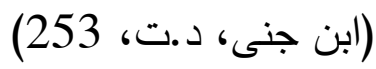

وعلى سبيل المثال يتضمن حقل (فتح) كثيرًا من الأوزان الصرفية مثل اسم الفاعل (فاتح)، وصيغة المبالغة (فتَّاح)، واسم المفعول(مفتوح)، واسمى الزمان والمكان (مَفْتَح)، واسم الآلَة

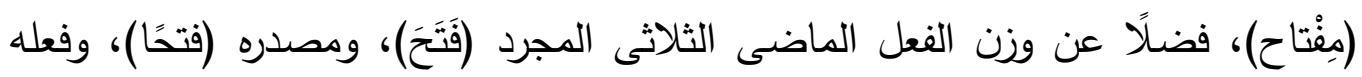
المضارع (يفتح)، والأمر منه (افتح)، وأوزان الفعل المزيد(فاتَح- انفَتَح- افتَتَح- تفتَّح واستقتح) ويتسع الحقل ليشمل المشتقات الممكنة من كل فعل من الأفعال المزيدة. 


\section{الجمعية المصرية للقر اعة والمعرفة عضو الجمعية الدولية للمعرفة}

2.الحقول الدلالية للأسماء: وهذا النوع من الحقول موجود فى اللغة العربية أكثر من غيرها من اللغات، فقد تدل صيغة "فِعالة" على المهن والصنائع، مثل: (جِزارة- سِيفانةنِجارة)، فى حين تدل صيغة "مفعل" على المكان، مثل: (مسبح- مربد - منزل). وقد يقتصر الحقل على صيغة صرفية واحدة تضم مجموعة كبيرة من الكلمات مثل صيغة



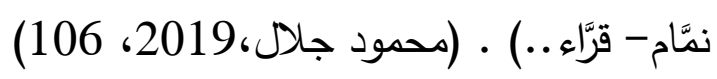

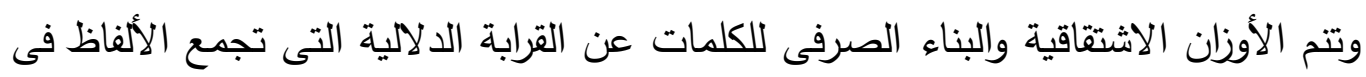



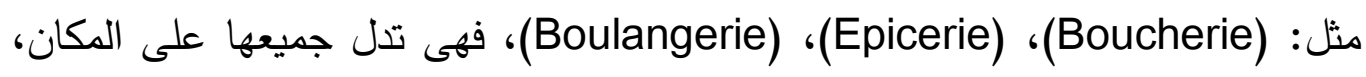




فى أنها تتصل فيما بينها فى العلم، ويختلف كل علم عن الآخر فى اختصاص معين. (و) توظيف الحقول الدلالية الصرفية فى تنمية مهارات الأداء الكتابى: تقدم الحقول الدلالية الصرفية للكاتب قائمة من المفردات اللغوية الاثتقاقية؛ لتكون مادة

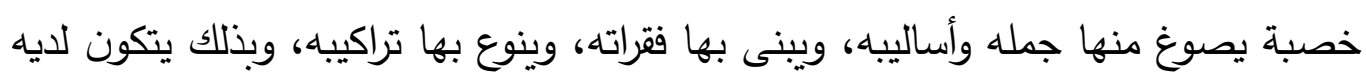
معجمًا لغويًا يستعين بكلماته فى أثناء الكتابة.

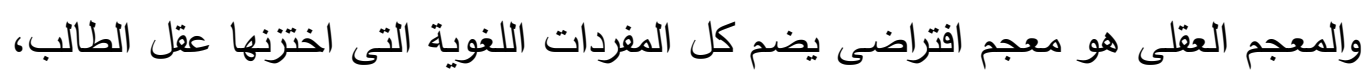





$$
\text { المفردات. (آية نصر، 2016، 216) }
$$

وتثير دراسة هواكينغ، ويونفى (45) - yunfei, D\& huaqing,H,2015, 40) إلى أن الهيف من تدريس المفردات هو بناء المعجم العقلى للطلاب على أساس الفهم الصحيح 


\section{الجمعية المصرية للقر اعة و المعرفة عضو الجمعية الدولية للمعرفة ILA}

لتنظيم المعجم العقلى، ووسائل تنميته، ويقترح الباحثان تدريس الكلمات الجديدة باستخدام


الكلمات، وتعليم القواعد الصرفية - وبخاصة- قواعد اشتقاق الكلمات. فمعطيات النظام الصرفى يجب أن تتبوأ مكانتها عند التخطيط لتدريس المفردات، فالنظام الصرفى للغة يبنى فى اللغة العربية على ثلاث دعائم: أولها مجموعة من المعانى الصرفية التى يرجع بعضها إلى تقسيم الكلام، ويعود بعضها إلى تصريف الصيخ، ثانيها


أدوات، وقد يدل على المبنى دلالة عدمية بالحذف أو الاستتار حيث تغنى القرينة فى لى

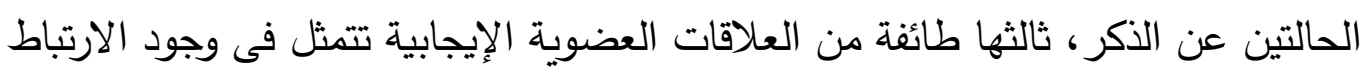
بين المبانى، وطائفة أخرى من القيم الخلافية أو المقابلات وهى وجود الاختلاف بين الإني

$$
\text { مما سبق يمكن القول: المعانى. (محود جلال،2019، 98) }
$$

• إن المتعلم يستطيع أن يتخير ألفاظه ومفرداته اللغوية من بين مجموعة من الكلمات التى ضمها معجمه العقلى، فتصنيف المفردات فى حقول دلالية يسهل على المتعلم الاختيار من بينها، واستخدامها فى بناء فقراته والتعبير عن فكره. يمكن توظيف الحقول الدلالية الصرفية بأن يستطيع الطالب إكمال خريطة لحقل

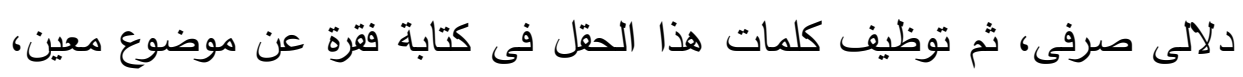
وفيما يلى مثال للحقل الدلالى الصرفى (فَعَل)، فيمكن من خلال هذا الحقل تحقيق معان متعددة، منها: 


\section{الجمعية المصرية للقر اعة و المعرفة عضو الجمعية الدولية للمعرفة ILA}

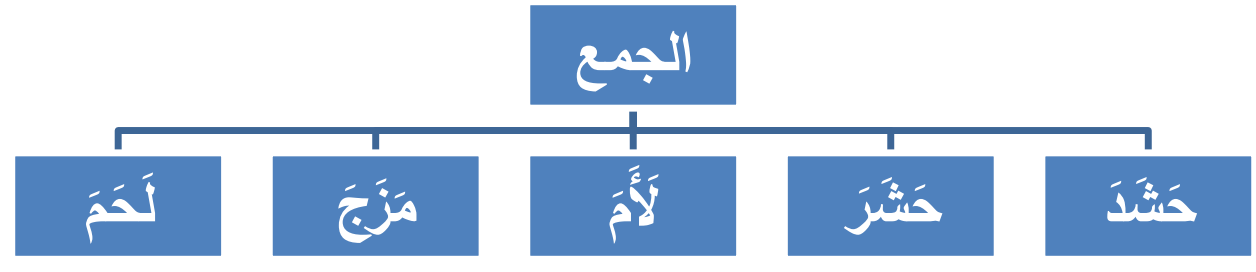

شكل(1) الحقل الدلالى الصرفى للأفعال الثلاثية المجردة من ضرب (فَعَل) تفيد معنى

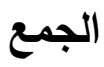

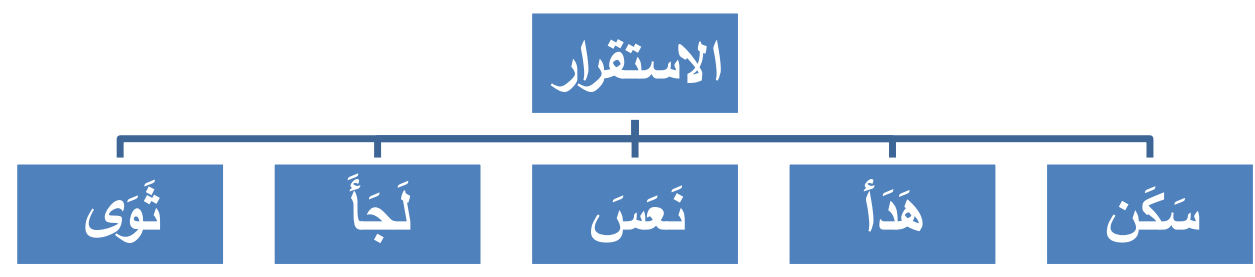

شكل(2) الحقل الدلالى الصرفى للأفعال الثلاثية المجردة من ضرب (فَعَل) تفيد معنى الاستقرار

ويمكن للطالب أن يوظف الكلمات التى تنتمى للحقول الصرفية للمشتقات، فكلمة (كتب) يؤخذ منها:

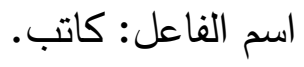

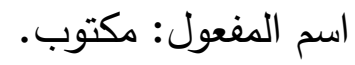

اسم المكان: مكتب - مكتبة. 


\section{الجمعية المصرية للقر اعة والمعرفة عضو الجمعية الدولية للمعرفة}

\section{نتائج البحث:}

استهدف البحث الإجابة عن الأسئلة الآتية:

1. ما مهارات الأداء الكتابى اللازمة لطلاب الصف الأول الثانوى؟

2. ما مستويات طلاب الصف الأول الثانوى فى مهارات الأداء الكتابى؟

3. ما الاستراتيجية المقترحة لتمية مهارات الأداء الكتابى لدى طلاب الصف

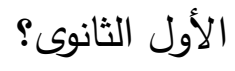

4. ما فاعلية الاستراتيجية المقترحة فى تتمية مهارات الأداء الكتابى لدى طلاب

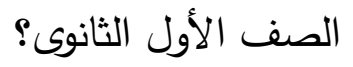

وفيما يلى الإجابة عن الأسئلة السابقة:

أولًا: مهارات الأداء الكتابى اللازمة لطلاب الصف الأول الثانوى:

توصلت الدراسة إلى قائمة بمهارات الأداء الكتابى اللازمة لطلاب الصف الأول الثانوى، وهى:

1. يوظف المفردات التى تتنمى للحقول الصرفية للمشتقات: اسم (الفاعل، المفعول،

$$
\text { الزمان، المكان) فى التعبير عن فكره. }
$$

2. يعبر عن الموقف مميزًا دلالات الصيخ الصرفية للفعل الثلاثى المزيد على وزن

$$
\text { "استفعَل". (الطلب - الاستعطاء - الإخبار ). }
$$

3. يكتب مستخدمًا صيخ الأفعال للتعبير عن المعنى المراد بدقة. 


\section{ILA الجمعية المصرية للقر اءة والمعرفة عضو الجمعية الدولية للمعرفة}

4. يستخدم التتوعات الصرفية للكلمات (فُعَالة- دُفَاعَلة- فُعَال) بما يناسب الموضوع.

5. يستخدم كلمات لها نفس المبنى مع اختلاف المعنى فى عرضه لفكر الموضوع. مثل:

$$
\text { (ثار - مار - مار ) - (ث) }
$$

ثانيًا: مستويات طلاب الصف الأول الثانوى فى مهارات الأداء الكتابى: طبقت الباحثة اختبار الأداء الكتابى تطبيقًا قبليًا على عينة من طلاب الصف

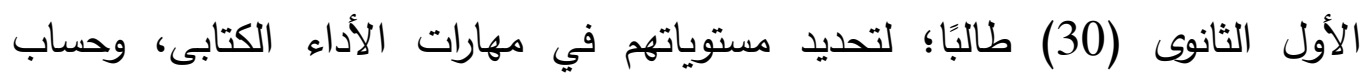
متوسطات الدرجات والنسب المئوية لها، كما هو موضح بالجدول الآتى: جدول(1) يوضتح مستويات الطلاب فى مهارات الأداء الكتابى

\begin{tabular}{|c|c|}
\hline نسبة مستوي الطلاب في مهارات الأداء الكتابي & 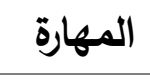 \\
\hline 29.17 & 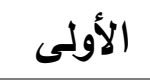 \\
\hline 25 &  \\
\hline 26.39 &  \\
\hline 25 & 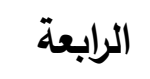 \\
\hline 29.17 & 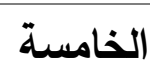 \\
\hline
\end{tabular}

وبهذا يتم قبول الفرض الأول للدراسة والذى ينص على أنه تقل مستويات طلاب الصف الصف الته الأول الثانوى عن مستوى (50\% ) في مهارات الأداء الكتابى. لئ.

ثالثًا: الاستراتيجية المقترحة لتنمية مهارات الأداء الكتابى فى ضوء الحقول الالالية الصرفية:

توصل البحث إلى استراتيجية مقترحة تتضمن مجموعة من الإجراءات؛ لتنمية مهارات الأداء الكتابى في ضوء الحقول الدلالية الصرفية يمكن عرضها فيما يلى: 


\section{الجمعية المصرية للقر اعة والمعرفة عضو الجمعية الدولية للمعرفة}

1. عرض الصيغة الصرفية: يقوم المعلم بعرض صيغة صرفية على الطلاب، ويطلب منهم اشتقاق أوزان صرفية جديدة من الصيغة المعطاة.

2. التنظيم فى مخططات: يطلب المعلم من طلابه توسيع الحقل الصرفى للكلمة ليشمل تتوعات صرفية متعددة (المشتقات- المجرد والمزيد- كلمات على وزن

$$
\text { معين - الصحيح والمعتل- صيخ المبالغة). }
$$

3. استخلاص دلالات الكلمات: يقوم المعلم بعرض لكيفية تصنيف المفردات الصرفية لاستخلاص دلالاتها ومعرفة المقصد منها ك: (الاستعطاء- الجمع - الاستخبار).

4. النمذجة اللغوية: يعرض المعلم نموذجًا يوضح كيفية توظيف بعض مفردات الحقل الدلالى الصرفى فى كتابة فقرة عن موضوع معين. 5. كتابة الطلاب: يطلب المعلم من طلابه توظيف كلمات الحقل الصرفى فى كتابة فقرة أخرى من أسلوبهم. 6. تقويم الأداء: يعرض الطلاب كتاباتهم على زملائهم ويتلقى الطلاب تعليقات

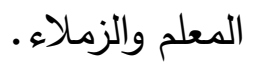

رابعًا: فاعلية الاستراتيجية المقترحة فى تنمية مهارات الأداء الكتابى فى ضوء الحقول الدلالية الصرفية: للإجابة عن هذا السؤال تم طرح الفرضين:

1. يوجد فرق دال إحصائيًا >05 0.05 بين متوسطى درجات المجموعة التجريبية فى التطبيقين القبلى والبعدى فى اختبار مهارات الأداء الكتابى لصالح التطبيق

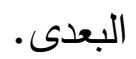




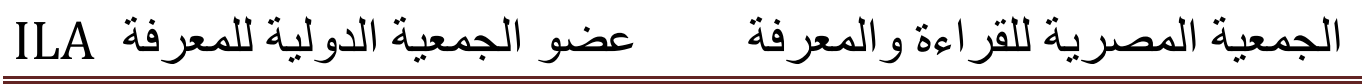

2. تحقق الاستراتيجية المقترحة درجة فاعلية كبيرة فى تتمية مهارات الأداء الكتابى لطلاب الصف الأول الثانوى.

ولاختبار صحة الفرض الذى ينص على " يوجد فرق دال إحصائيًا عند مستوي ج 0.05 بين متوسطى درجـات المجموعـة التجرببية فى التطبيقين القبلى والبعدى فى اختبار مهارات الأداء الكتابى لصالح التطبيق البعدى "، قامت الباحثة بما يلى : - حساب دلالة الفروق بين متوسط درجات طلاب مجموعة البحث فى التطبيقين (T- "القبلى والبعدى لاختبار مهارات الأداء الكتابى، من خلال تطبيق اختبار "ت ، "SPSS" للعينات المرتبطة، وذلك باستخدام حزمة البرامج الإحصائية test) والجدول الآتى يوضح ذلك:

\section{جدول( 2 )}

نتائج اختبار "ت" للعينات المرتبطة لدلالة الفروق بين متوسطى درجات مجموعة البحث فى

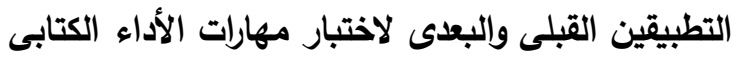

\begin{tabular}{|c|c|c|c|c|c|}
\hline مستوى & درجات & قيمة "ت" & الانحراف & الفروق بين & عدد طلاب \\
\hline الدلالة & الحرية & المحسوبة & المعياري & المتوسطين & مجموعة البحث \\
\hline 0.001 & 29 & 8.047 & 4.492 & 6.6 & 30 \\
\hline
\end{tabular}

ويتضح من جدول (2) أن قيمة "ت" تساوى (8.047) عند درجة حرية 29، والدلالة المحسوبة لها كمبيوتريًا(0.001)، وحيث إن هذه الدلالة أقل من 0.05، فإن قيمة "ت" دالة، وعليه يتم قبول الفرض البحثى الذى ينص على: "يوجد فرق ذو دلالة إحصائية عند مستوى > 0.05 بين متوسطي درجات طلاب مجموعة البحث فى التطبيقين القبلى والبعدى لاختبار مهارات الأداء الكتابي لصالح التطبيق البعدى". 


\section{الجمعية المصرية للقر اعة و المعرفة عضو الجمعية الدولية للمعرفة ILA}

- وللتحقق من فاعلية الاستراتيجية المقترحة فى تنمية مهارات الأداء الكتابى لطلاب الصف الأول الثانوى، قامت الباحثة بما يلى:

- - حساب نسبة الفاعلية لـ"مالك جوجيان" لاختبار مهار ات الأداء الكتابى:

جدول (3)

نسبة الفاعلية لـ"ماك جوجيان" مقارنة بالتطبيق القبلى

\begin{tabular}{rrrrr}
\hline التطبيق القبلى & \\
\hline \\
\hline 0.6
\end{tabular}

ويوضح الثكل التالى متوسطى الارجات الكلية لطلاب المجموعة التجريبية فى التطبيقين القبلى والبعدى لاختبار مهارات الأداء الكتابى:

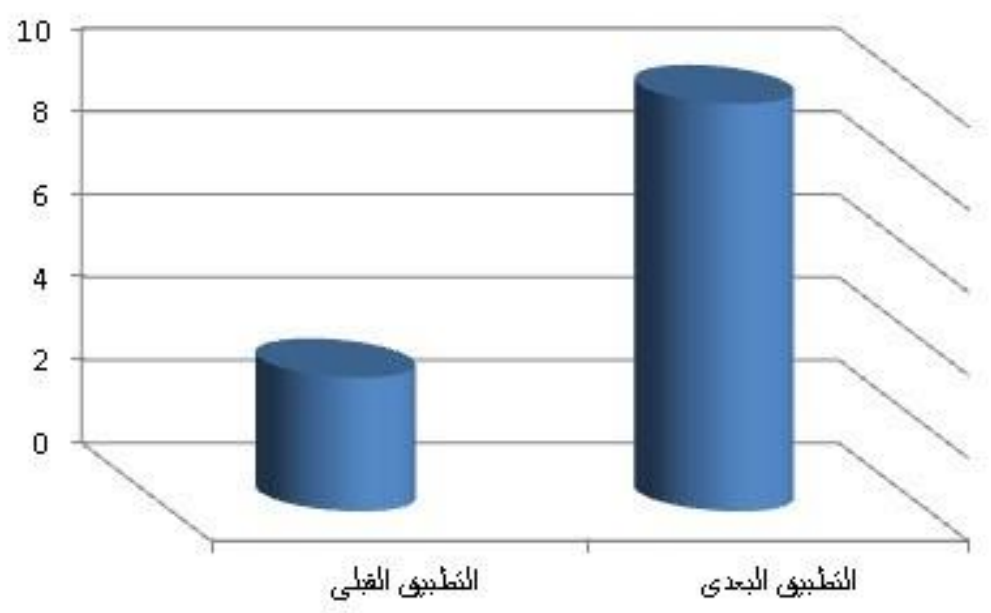

شكل (3) يوضح متوسطى الارجات الكلية لطلاب المجموعة التجريبية في التطبيقين القبلى والبعدى لاختبار مهارات الأداء الكتابى 


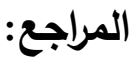



إنتصار عطية(2019). فاعلية برنامج مقترح قائم على استراتيجية التعلم التعاونى لتتمية بعض مهارات


التربية، جامعة بنى سويف.

أحمد حسانى(1994). مباحث فى اللسانيات . ديوان المطبوعات الجامعية، الجزائر . أحمد عزوز(2002). جذور نظرية الحقول الدلالية فى التراث اللغوى. مجلة التراث العربى، دمشق،85، $.82-74$



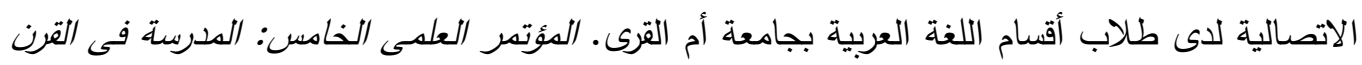

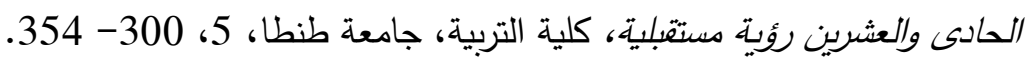
أحمد مختار عمر (1988). علم الدلالة. القاهرة: عالم الكتب. أمانى بدر(2019). العلاقة بين مستويات الأداء الكتابى والقراءة الموسعة في المرحلة الابتدائية. مجلة

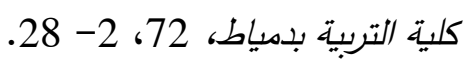

آية نصر (2016). استراتيجية مقترحة فى ضوء نظرية الحقول الدلالية لتتمية بعض مهارات الإبداع

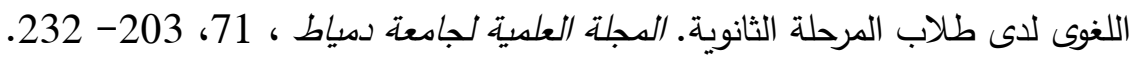
ابن جنى عثمان بن عمر (د.ت). الخصائص. الطبعة الثانية، تحقيق تحمح النجار ، بيروت: دار الهذى. حلى خليل(2003). مقدمة لدراسة التراث الهعجىى العربى. القاهرة: دار المعرفة الجامعية. رائد خضر ، محمد الخوالدة، نصر مقابلة، محمد ياسين(2012). خصائص نعلم اللغة العربية الفعال"دراسة مقارنة". المجلة الأردنية فى العلوم التربوية، 8(2)، 167 - 181 - 181. 


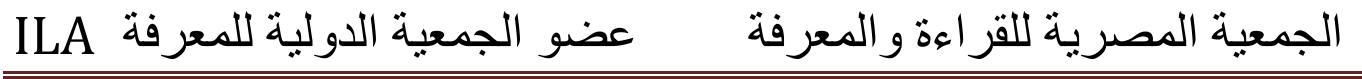

رانيا عمر (2020). برنامج أنشطة قائم على نظرية الحقول الدلالية باستخدام محفزات الألعاب، وفاعليته في تتمية المفردات اللغوية ومهارات التفكير التحليلى لدى تلاميذ الصف التفرية الرابع الابتدائى. رشدى أحمد طعيمة، محم السيد مناع (2001م). تدريس العربية فى التعليم العام، نظريات وتجارب . ط2، دار الفكر العربى، القاهرة

زكى كريم حسام الدين(1985). أصول تراثية فى علم اللغة. ط2، القاهرة: مكتبة الأنجلو المصرية.


الثاني الأساسي في دولة الإمارات العربية المتحدة. مجلة المنار ، 3(23). سلوى بصل(2015). برنامج مقترح قائم على التعلم المنظم ذاتيًا لتتمية بعض مهارات الأداء الكتابى فى التى


.166

سليمان فياض(1990). الحقول الدلالية الصرفية للأفعال العربية. الرياض: دار المريخ. صلاح الدين زرال(2008). الظاهرة الدلالية عند علماء العربية القدامى حتى نهاية القرن الرابع الهجرى.



عبد الجليل لغرام(2018). مفهوم نظرية الحقول الدلالية. مجلة الحكمة للدراسات الأدبية واللغوية، 13، $.227-214$

عبد الجليل منقور(2001). علم الدلالة أصوله ومباحثه فى التراث العببى. دمشق: منشورات اتحاد

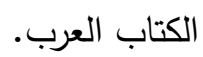

على الحلاق(2007). استخدام استراتيجيات التعبير الكتابى الحر والموجه والمقيد فى تتمية مهارات

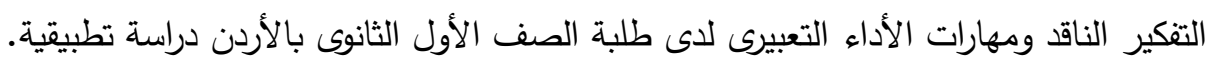
على عبد المنعم(2012). فاعلية برنامج مقترح قائم على نموذج أبعاد التعلم فى تتمية الأداء الكتابى التى والتفكير الناقد لدى طلاب الصف الأول الثانوى، رسالة دكتوراه غير منشورة، كلية التربية، جامعة الزقازيق. 


\section{الجمعية المصرية للقراعة والمعرفة عضو الجمعية الدولية للمعرفة ILA}

ماهر عبد البارى(2008). برنامج لتتمية الأداء الكتابى لطلاب المرحلة الثانوية باستخدام بعض استراتيجيات ما وراء المعرفة، رسالة دكتوراه غير منشورة، كلية التربية، جامعة بنها.

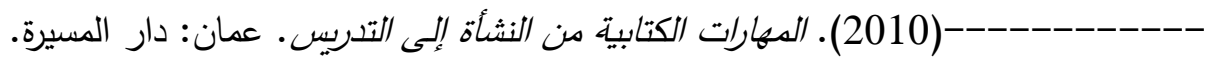
محمد النجار ، وأحمد الهوارى، وسعد مصلوح (2001). الكتابة العربية مهاراتها وفنونها ـ الكويت: مكتبة دار

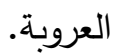

محمد ناثر (2011). فعالية نظرية الحقول الدلالية فى التعبير الوصفى لتتمية مهارة الكلام. رسالة ماجستير ،

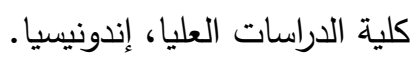

محمود جلال الدين سليمان (2009م). فاعلية استخدام مدخل عمليات الكتابة فى تتمية الأداء الكتابى


التدريس، العدد 148، يوليو •

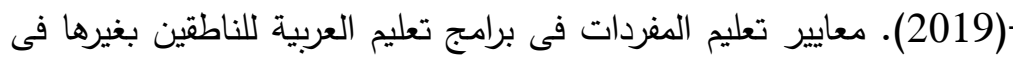


مختار حسين(2006). سلسلة تعليم التعبير الكتابى. الرياض: مكتبة العبيكان للنشر.

مرفت البسيونى(2019). فاعلية برنامج مقترح في التعبير قائم على مدخل عمليات الكتابة المعززة بالويب فى تتمية الأداء الكتابى والتثكير الإبداعى وخفض قلق الكتابة لكتئ لدى طالبات الصف الأول الثانوى.

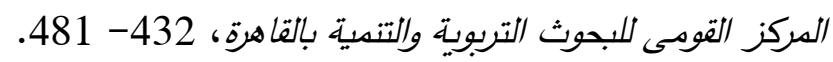


Baker,M.(2003). Linguistic Differences And Language.Cognitive Sciences, 8, 349-353.

Elaine, R\& Tiffany, L\&Louise, C.(2000). Adynamic systems Approach to Writing Assessment in Student With Language Learning Problem. Topics in Language Disorders, 20( 4), 45-64.

Qian,D\& Schedl,M. (2004). Evaluation of AN In-depth Vocabulary Knowledge Measure For Assessing Reading Performance, SAGE journal, First published January(1), 82- 87.

Yunfei,D \& Huaqing,H (2015). The Mental Lexicon and English Vocabulary Teaching English Language Teaching, Canadian Center of Science and Education, 8(7), 40-45. 